\title{
One Lung Ventilation: How can we Prevent Lung Injury after Thoracic Surgery?
}

\section{Kiyoyasu Kurahashi*}

Department of Anesthesiology and Critical Care Medicine, Yokohama City University Graduate School of Medicine, Japan

After thoracic surgery, about $2 \%$ to $5 \%$ patients develop lung injury and the mortality rate for those patients is high, $25 \%$ to $100 \%$ [1] Therefore, it is important to prevent lung injury after thoracic surgery to improve outcomes of patients undergoing thoracic surgery. The question is "how can we do so?"

The causes for the development of lung injury are reported as surgical trauma, lung overinflation, pulmonary hypertension or hyper-perfusion, lymph drainage impairment, oxidative stress, and reperfusion injury [2,3]. Pre-existing conditions such as malignancy [4], sepsis [5], or lung diseases are other factors that may prime lungs for susceptibility to lung injury. Risk factors [6] for postoperative lung injury are evident (Table 1). Any single risk factor is less possible to cause lung injuries by itself; but combined effects of some of the factors would lead lung injury (multiple hit theory) [7].

The biophysiological etiology of postoperative lung injury is also multi factorial. Ventilator induced lung injury due to high tidal volume /high transmural pressure owing to reduced lung volume, pulmonary capillary stress failure due to reduced vascular bed, oxygen stress caused by increased inspiratory oxygen fraction during One Lung Ventilation (OLV), ischemia / reperfusion injury of the non-ventilated lungs during OLV, and surgical injury and stress [13]. In addition, recent laboratory findings suggested that tissue hypoxia of the collapsed lungs during OLV is the major cause of lung injury [14]. The authors applied 3 $\mathrm{cm} \mathrm{H}_{2} \mathrm{O}$ of Continuous Positive End-Expiratory Pressure (CPAP) to the collapsed lungs and found that the CPAP increased perfusion of the collapsed lungs, decreased mRNA expressions of hypoxia-related genes, and reduced inflammatory cytokines.

Mechanical ventilation doesn't cause lung injury by itself; however, conventional mechanical ventilation (tidal volume of 10-12 ml/kg ideal body weight) may induce lung injury if lungs are primed by systemic inflammation or during major surgery. Tidal volume should be reduced to about $5 \mathrm{ml} / \mathrm{kg}$ ideal body weight during OLV. A brief outline of the lung protective strategies is to reduce tidal volume, apply open lung approach with Positive End-Expiratory Pressure (PEEP) and repeated lung recruitment maneuver, and avoid any lung lesion to be hypoxic.

In conclusion, OLV itself has a potential hazard to ventilator induced lung injury. Coexisting conditions including malignancy,

\begin{tabular}{|l|l|l|}
\hline \multicolumn{1}{|c|}{ Phase } & \multicolumn{1}{|c|}{ Factors } & \multicolumn{1}{c|}{ Reference } \\
\hline Pre-operative & Chemotherapy & Parquin1996 [6] \\
\hline & Radiation & Parquin1996 [6] \\
\hline & Alcohol abuse & Licker2003 [7] \\
\hline & Pulmonary fibrosis & Chida2008 [8] \\
\hline Intra-operative & Pneumonectomy & Licker2003 [7] \\
\hline & Rt. pneumonectomy (as compared with It.) & Nohl-Oser1972 [9] \\
\hline & Intraoperative fluid overload (> 2L) & Parquin1996 [6] \\
\hline & High tidal volume / pressure during OLV & Jeon2009 [10] \\
\hline & High insp. oxygen fraction & Grocott2008 [11] \\
\hline Post-operative & Perioperative fluid balance (<1.5L) & Evans2012 [12] \\
\hline & Remaining lung perfusion (<55\%) & Parquin1996 [6] \\
\hline
\end{tabular}

Table 1: Risk factors for lung injury after thoracic surgery. preoperative radiation and chemotherapies, and the ongoing major surgical injury and stress would have primed the lungs for Acute Respiratory Distress Syndrome (ARDS). Therefore, during and after the thoracic surgery, we should eliminate as many known risk factors for post-operative lung injury as possible. That includes unnecessary hyperoxia, lung overinflation, fluid overload, and lung collapse and these will be facilitated by reducing inspiratory oxygen fraction, reducing tidal volume, applying PEEP and lung recruitment maneuver to the ventilated lungs, and applying CPAP to collapsed lungs.

\section{Reference}

1. Licker M, Fauconnet P, Villiger Y, Tschopp JM (2009) Acute lung injury and outcomes after thoracic surgery. Curr Opin Anaesthesiol 22: 61-67.

2. Eichenbaum KD, Neustein SM (2010) Acute lung injury after thoracic surgery. $J$ Cardiothorac Vasc Anesth 24: 681-690.

3. Bigatello LM, Allain R, Gaissert HA (2004) Acute lung injury after pulmonary resection. Minerva Anestesiol 70: 159-166.

4. Misthos P, Katsaragakis S, Milingos N, Kakaris S, Sepsas E, et al. (2005) Postresectional pulmonary oxidative stress in lung cancer patients. The role of one-lung ventilation. Eur J Cardiothorac Surg 27: 379-382.

5. Villar J, Blanco J, Zhang H, Slutsky AS (2011) Ventilator-induced lung injury and sepsis: two sides of the same coin? Minerva Anestesiol 77: 647-653.

6. Parquin F, Marchal M, Mehiri S, Hervé P, Lescot B (1996) Post-pneumonectomy pulmonary edema: analysis and risk factors. Eur J Cardiothorac Surg 10: 929932.

7. Licker M, de Perrot M, Spiliopoulos A, Robert J, Diaper J, et al. (2003) Risk factors for acute lung injury after thoracic surgery for lung cancer. Anesth Analg 97: 1558-1565.

8. Chida M, Ono S, Hoshikawa Y, Kondo T (2008) Subclinical idiopathic pulmonary fibrosis is also a risk factor of postoperative acute respiratory distress syndrome following thoracic surgery. Eur J Cardiothorac Surg 34: 878-881.

9. Nohl-Oser HC (1972) An investigation of the anatomy of the lymphatic drainage of the lungs as shown by the lymphatic spread of bronchial carcinoma. Ann R Coll Surg Engl 51: 157-176.

10. Jeon K, Yoon JW, Suh GY, Kim J, Kim K, et al. (2009) Risk factors for postpneumonectomy acute lung injury/acute respiratory distress syndrome in primary lung cancer patients. Anaesth Intensive Care 37: 14-19.

11. Grocott HP (2008) Oxygen toxicity during one-lung ventilation: is it time to reevaluate our practice? Anesthesiol Clin 26: 273-280.

12. Evans RG, Naidu B (2012) Does a conservative fluid management strategy in the perioperative management of lung resection patients reduce the risk of acute lung injury? Interact Cardiovasc Thorac Surg 15: 498-504.

*Corresponding author: Kiyoyasu Kurahashi, Department of Anesthesiology and Critical Care Medicine, Yokohama City University Graduate School of Medicine Japan, E-mail: kiyok@yokohama-cu.ac.jp

Received November 22, 2012; Accepted November 23, 2012; Published November 26, 2012

Citation: Kurahashi K (2012) One Lung Ventilation: How can we Prevent Lung Injury after Thoracic Surgery? J Pulmon Resp Med 2:e120. doi:10.4172/2161-105X.1000e120

Copyright: @ 2012 Kurahashi K. This is an open-access article distributed under the terms of the Creative Commons Attribution License, which permits unrestricted use, distribution, and reproduction in any medium, provided the original author and source are credited. 
Citation: Kurahashi K (2012) One Lung Ventilation: How can we Prevent Lung Injury after Thoracic Surgery? J Pulmon Resp Med 2:e120. doi:10.4172/2161-105X.1000e120

Page 2 of 2

13. Baudouin SV (2003) Lung injury after thoracotomy. Br J Anaesth 91: 132-142.

14. Tojo K, Ota S, Baba Y, Koga M, Goto T, et al. (2012) Application of continuous positive airway pressure to the collapsed lung during one-lung ventilation attenuates lung inflammation via HIF-1 pathway. American Society of Anesthesiologists Annual meeting Washington DC, USA 